\title{
Burden of disease from atrial fibrillation in adults from seven countries in Latin America
}

This article was published in the following Dove Press journal:

International Journal of General Medicine

2 September 2014

Number of times this article has been viewed

Luz Cubillos'

Alexandra Haddad ${ }^{2}$

Andreas Kuznik ${ }^{3}$

Joaquin Mould-Quevedo ${ }^{4}$

'Medical Affairs, Pfizer Inc., New York, NY, USA; ${ }^{2}$ Gerente Médico Portafolio Cardiovascular, Dirección Médica, Pfizer Mexico, Mexico City, Mexico; ${ }^{3} \mathrm{Global}$ Health Economics and Outcomes Research, Pfizer Inc., New York, NY, USA; ${ }^{4}$ Health Economics and Outcomes Research, Latin America and Primary Care, Pfizer Inc., New York, NY, USA

The affiliations given here are those from at the time the research was done.
Correspondence: Luz Cubillos

Medical Affairs, Pfizer Inc., 235 East 42nd

Street, New York, NY 10017, USA

Tel + I 2127333326

Fax + I 646 44| 46/3

Email luzangela.a.cubillos@pfizer.com
Background: While some international studies have published epidemiologic overviews of atrial fibrillation (AF) for the Latin America region, detailed data at the national level are lacking. The aim of this study was to estimate the burden of disease and morbidity associated with AF in adults over 40 years of age in Argentina, Brazil, Chile, Colombia, Mexico, Peru, and Venezuela.

Methods: National health care system databases for each country in the analysis were used to identify cases of AF during 2010 based on ICD-10 codes. Patient comorbidities and treatment patterns in each country were assessed based on available data and extrapolation from relevant published information where local data were incomplete or unavailable. The prevalence of AF in each country was estimated using country-specific, national census data, and assumptions based on a review of the available literature.

Results: Patients in outpatient or hospital care represented over half of the estimated total cases of AF, of whom around $60 \%$ were treated as outpatients. Across the seven countries analyzed, $74.5 \%$ of AF cases were adults $\geq 60$ years old. However, with increasing age, the proportion of individuals with AF receiving treatment within the national health care systems decreased overall across all seven countries. The most commonly reported comorbidities associated with AF included arterial hypertension $(51 \%-57 \%)$, heart failure $(14.5 \%-30 \%)$, diabetes $(12 \%-36.5 \%)$, and stroke (3\%-12.7\%).

Conclusion: This epidemiologic survey quantifies the scale of the challenge posed by AF to the various national health care systems in Latin America. Overall, ambulatory patients in the national health care systems carry a high risk of developing a stroke, yet a significant proportion of these patients do not receive appropriate anticoagulant therapy.

Keywords: Latin America, stroke, atrial fibrillation, burden of disease, epidemiology, anticoagulation

\section{Introduction}

Atrial fibrillation (AF) is the most common cardiac arrhythmia, with nonvalvular AF (defined as AF in the absence of rheumatic mitral valve disease, a prosthetic heart valve, or mitral valve repair) comprising the majority of AF cases. ${ }^{1}$ In general, AF is more prevalent among men than women and occurs more frequently among people of advanced age, with the incidence of AF rising from $<0.1 \%$ year in patients aged $<40$ years to approximately $1.5 \%$ /year in women and $2 \% /$ year in men aged $>80$ years. $^{2}$ The prevalence of AF is predicted to increase in the coming decades alongside an aging population in the modern world. ${ }^{3,4}$

$\mathrm{AF}$ is associated with a 5-fold increased risk of stroke, and one in five strokes are attributed to this arrhythmia..$^{5}$ Stroke risk in AF is dependent on major risk 
factors, including prior stroke, transient ischemic attack, thromboembolism, and older age ( $\geq 75$ years). Vitamin $K$ antagonists (VKAs) reduce stroke risk in patients with AF by approximately two-thirds compared with placebo and by $38 \%$ compared with antiplatelet therapy. ${ }^{6}$ Although they have since been updated, guidelines available prior to 2010 recommended long-term oral anticoagulation with VKA dose-adjusted to an international normalized ratio between two and three for patients with $\mathrm{AF}$ who are at intermediate $\left(\mathrm{CHADS}_{2}\right.$ score of 1$)$ and high $\left(\mathrm{CHADS}_{2}\right.$ score of $\left.\geq 2\right)$ risk of stroke. ${ }^{7,8}$

While some international studies have published epidemiologic overviews of AF for the Latin America region, ${ }^{9}$ detailed data at the national level are lacking. Local Latin American studies on AF prevalence exist but are small, with data often recorded at a single hospital. ${ }^{10-12}$ National registry studies for some Latin American countries are underway, but published data are not yet available. ${ }^{13}$ Though there is lack of data, the large population in Latin America combined with an aging population suggests that the number of patients with $\mathrm{AF}$ in the region is likely to be substantial. ${ }^{14}$ Data from a global registry study indicates that the rate of AF-related strokes in South America is comparable to that of Western Europe and the US, indicating a similar burden of disease for the region. ${ }^{15}$ However, in the same registry, the 1-year mortality risk for patients with AF was almost twice as high.

The objective of the present investigation was to estimate the morbidity resulting from AF in adults over 40 years of age in Argentina, Brazil, Chile, Colombia, Mexico, Peru, and Venezuela, using local databases and information from their respective national health care systems. Where data were unavailable, extrapolations were made based on available data and estimates from the published literature.

\section{Materials and methods}

\section{Information from national databases}

Local sources from the different health care systems in each country ${ }^{16-29}$ were used to determine the number of inpatient and outpatient cases of AF (ICD-10: I48) reported up to the year 2010 (values normalized to 2010), distributed by age group (40-49, 50-59, 60-69, 70-79, and $\geq 80$ years of age) and by sex. Where available, data on comorbidities and treatment were obtained from the national health care system databases.

Based on assessment of the ICD-10 codes recorded in the databases, local notification sources did not allow for differential determination of cases of valvular and nonvalvular AF. In addition, comorbidity and patient treatment data were not available for every patient in the national health care system databases. To better estimate morbidity from AF in the selected seven Latin American countries, a literature review was conducted of published epidemiologic data from Latin America and worldwide, with the aim of extrapolating from the available local data.

\section{Literature review}

A review of the published literature from the last 20 years to May 2011 was performed, focusing on the prevalence of AF in the total population by age group (40-49, 50-59, 60-69, 70-79, and $\geq 80$ years) and by type of AF (valvular or nonvalvular) in the selected Latin American countries. The MEDLINE, HealthSTAR, PsycINFO, Embase, ScienceDirect, Ovid, and Cochrane Library databases were searched for publications in English, as were the INBIOMED and LILACS databases for publications in Spanish and Portuguese. Queries used the following terms: atrial fibrillation, nonvalvular atrial fibrillation, valvular atrial fibrillation, epidemiology, prevalence, and Latin America, with equivalent terms used for the Spanish and Portuguese language searches. For inclusion in the analysis, publications were required to meet the following criteria: local data with the prevalence of AF among the total population, by age group, and by type of AF.

Fifty-two documents were identified in the initial search relating to the following Latin American countries: Mexico (eleven), Brazil (nine), Argentina (twelve), Chile (eight), Colombia (seven), Peru (three), and Venezuela (two). Of these, all but one did not fulfill the original inclusion criteria, primarily because they referenced international systematic reviews and not local information, and were excluded. Only one publication on AF in Mexico met all criteria for inclusion. Owing to the lack of qualifying studies in the medical literature for AF in Latin America, the search was then widened to include publications relating to AF in other geographic areas. Extending the search internationally identified 37 additional publications, nine of which met the modified inclusion criteria. These included publications in the US (five), UK (two), and Spain (two). A summary of articles identified by the literature search is shown in Figure 1.

\section{Estimation of AF prevalence}

In the absence of local epidemiologic data, AF prevalence rates obtained from the published literature were used to estimate the prevalence of AF by age group and by type of AF in each of the Latin American countries included in the study. For the selected literature a meta-analysis, using Comprehensive 


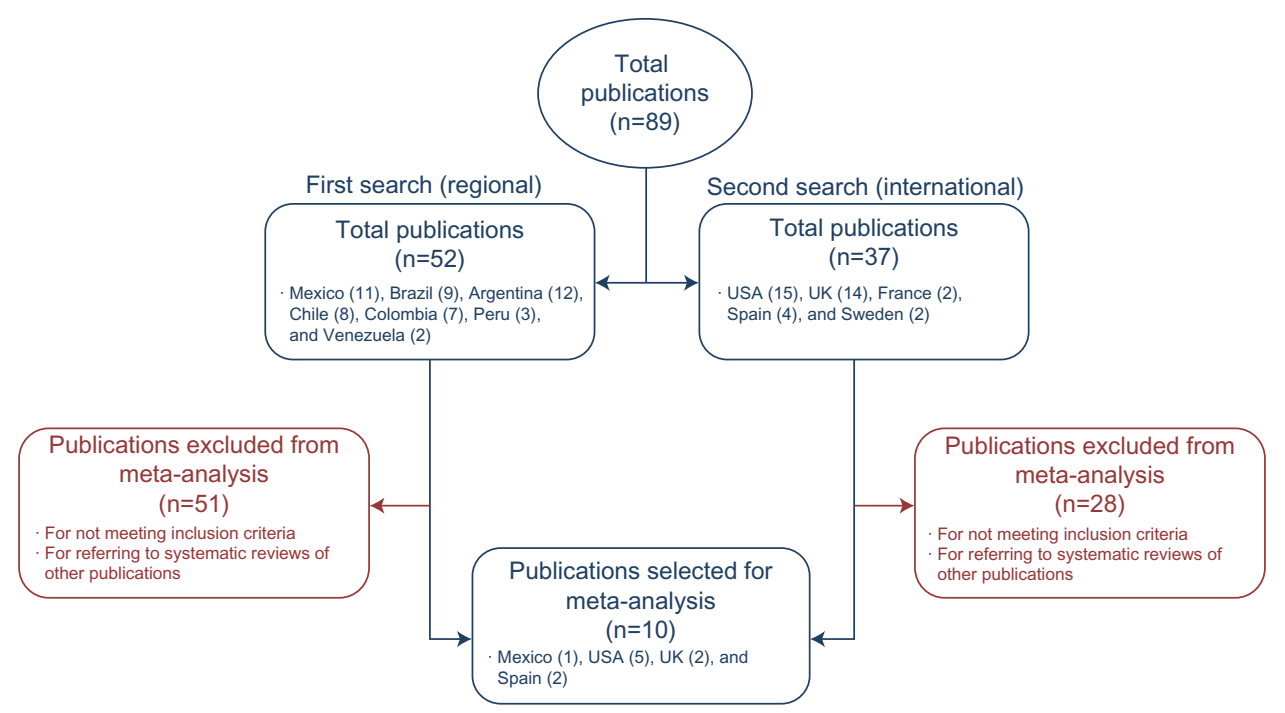

Figure I Article flow for the systematic literature review.

Meta-analysis Version 2 (Biostat, Inc., Englewood, NJ, USA), ${ }^{30}$ was carried out with the random effects method to estimate the absolute risk for the prevalence of AF by age group and by type of AF (valvular and nonvalvular). For this combinatorial analysis, studies were assigned weights using the Jared scale for weighting. The estimates of absolute risk were then applied to the data of the total population and corresponding population pyramids of each country to generate country-specific estimates of the prevalence of AF, which would include patients who had AF but were not diagnosed or receiving treatment. Relative weight of each study and 95\% confidence intervals were determined. Analyses of heterogeneity and of selection bias were carried out simultaneously ( $Q$-test, $P$-value, $I^{2}$-value, and funnel plot). AF cases were proportionately distributed as valvular or nonvalvular in each country according to the results of this meta-analysis. For comorbidities associated with AF, estimates were made based on local medical data and local literature. The main criterion for inclusion of local literature was published studies with data from the local population and not referencing international systematic reviews - similar to the criteria for AF prevalence (though without the requirement for a breakdown by age/type of AF).

Data on treatment were not available for all patients in the national health care databases but were available for a small proportion of them. To identify any relevant treatment trends, data from a few currently treated patients, along with additional information from local publications where available, were extrapolated to estimate the overall proportion of the total population receiving each treatment in each country..$^{10,31-34}$

\section{Results}

The estimated average prevalence of AF across the seven Latin American countries in this study was $1.6 \%$, based on available population data and estimates from the international literature. Table 1 shows the estimated prevalence by age group and among the total population $\geq 40$ years of age in each country. The data follow a clear trend, with prevalence increasing with age.

Based on data from the individual national health care systems, patients in outpatient or hospital care represented

Table I Total AF prevalence (cases, \%) in seven Latin American countries, by age group ${ }^{a}$

\begin{tabular}{llllllll}
\hline Age group (year) & Argentina & Brazil & Chile & Colombia & Mexico & Peru & Venezuela \\
\hline $40-49$ & $18,573(0.40 \%)$ & $103,203(0.41 \%)$ & $10,029(0.40 \%)$ & $22,970(0.40 \%)$ & $59,637(0.43 \%)$ & $13,625(0.41 \%)$ & $14,104(0.41 \%)$ \\
$50-59$ & $28,054(0.71 \%)$ & $134,117(0.72 \%)$ & $13,793(0.72 \%)$ & $29,699(0.72 \%)$ & $70,332(0.75 \%)$ & $16,480(0.72 \%)$ & $17,750(0.72 \%)$ \\
$60-69$ & $65,573(2.22 \%)$ & $247,364(2.26 \%)$ & $27,246(2.25 \%)$ & $55,581(2.26 \%)$ & $128,498(2.34 \%)$ & $32,034(2.24 \%)$ & $34,430(2.28 \%)$ \\
$70-79$ & $91,639(4.78 \%)$ & $271,939(4.90 \%)$ & $33,277(4.86 \%)$ & $70,250(4.94 \%)$ & $148,795(5.10 \%)$ & $40,04 \mid(4.90 \%)$ & $36,766(4.89 \%)$ \\
$\geq 80$ & $77,509(8.17 \%)$ & $143,662(8.26 \%)$ & $26,257(8.26 \%)$ & $48,467(8.17 \%)$ & $114,745(8.48 \%)$ & $23,935(8.31 \%)$ & $21,354(8.33 \%)$ \\
All population $\geq 40$ & $28 I, 348(1.95 \%)$ & $900,285(1.44 \%)$ & $110,602(1.68 \%)$ & $226,967(1.59 \%)$ & $522,007(1.58 \%)$ & $126, I 15(1.55 \%)$ & $124,404(1.47 \%)$ \\
\hline
\end{tabular}

Note: aEstimated from national demographic data and international literature.

Abbreviation: AF, atrial fibrillation. 
over half of the estimated total cases of AF, of whom around $60 \%$ were treated as outpatients (Table 2 ). Across the seven countries analyzed, $74.5 \%$ of AF cases were adults $\geq 60$ years old (Argentina, 81.5\%; Brazil, 71.4\%; Chile, 76.2\%; Colombia, 74.5\%; Mexico, 72.7\%; Peru, 73.8\%; and Venezuela, $72.2 \%$ ), with proportionately more men than women ( $57.2 \%$ versus $42.8 \%$, respectively). Comparing the estimated prevalence of AF in the total population (Table 1) with that by age group (Table 2) showed that, with increasing age, the proportion of individuals with $\mathrm{AF}$ receiving treatment within the national health care systems decreased overall across all seven countries. Based on estimates, nonvalvular AF predominated in these countries, accounting for $85.9 \%$ of all cases compared with $14.1 \%$ of cases attributed to VAF.

AF as the primary diagnosis and reason for medical care is relatively rare, and over $95 \%$ of cases across the seven national health care systems analyzed were identified as secondary or tertiary diagnoses, based on clinical findings in relation to other comorbidities such as stroke, hypertension, or heart failure. The most commonly reported comorbidities associated with AF included arterial hypertension $(54.3 \%$; range, $51 \%-57 \%)$, heart failure $(24.5 \%$; range, $14.5 \%-30 \%)$, diabetes $(22.3 \%$; range, $12 \%-36.5 \%)$, and stroke $(8.5 \%$; range, $3 \%-12.7 \%$ ).

Antithrombotic and anticoagulant treatments received by both inpatients (grouped as unfractionated heparin, low-molecular-weight heparin, and VKA) and outpatients (grouped as VKA, VKA plus acetylsalicylic acid [ASA], VKA plus ASA plus antiplatelets, and no treatment) for each country are summarized in Table 3. In all countries, the majority of outpatients received VKA or VKA plus ASA $(66 \%-75.8 \%)$ with the remainder receiving either no treatment $(18.3 \%-24.6 \%)$ or triple therapy with warfarin, ASA, and an additional antiplatelet (3.8\%-9.6\%). As expected, the use of unfractionated heparin was higher in inpatients $(53.9 \%-65.6 \%)$ with only a small percentage of inpatients receiving VKA therapy in any country $(7.4 \%-10.4 \%)$, and the remainder receiving low-molecular-weight heparin (26.6\%-37.1\%) - a reflection of the need for the physician to have more strict control over the level of anticoagulation.

\section{Discussion}

In this epidemiologic study, the distribution of cases reflects both an increase in AF among patients $\geq 60$ years of age and a strong association among the elderly, particularly in patients $\geq 80$ years of age - something that has been clearly demonstrated in multiple trials $s^{9,35-37}$ previously. Population distributions for these seven Latin American countries were very similar with respect to estimates of AF prevalence, and there was a clear trend for increased prevalence with increasing age, as seen in other studies. ${ }^{35,36,38}$ The aging populations in these Latin American countries, combined with the

Table 2 AF cases in seven Latin American countries, by age group, sex, comorbidity, type of AF, and inpatient status ${ }^{\mathrm{a}}$

\begin{tabular}{|c|c|c|c|c|c|c|c|}
\hline$\overline{\text { Cases }}$ & Argentina & Brazil & Chile & Colombia & Mexico & Peru & Venezuela \\
\hline $\begin{array}{l}\text { Total (\% of estimated } \\
\text { prevalence) }\end{array}$ & 145,557 (5।.7\%) & $480,108(53.3 \%)$ & $58,47 \mathrm{I}(52.9 \%)$ & I I 8,724 (52.3\%) & $279,747(53.6 \%)$ & $67,496(53.5 \%)$ & $66,066(53.1 \%)$ \\
\hline \multicolumn{8}{|c|}{ By age group, year (\% of estimated prevalence) } \\
\hline $40-49$ & $1 \mathrm{I}, 285(60.8 \%)$ & $62,643(60.7 \%)$ & $6,145(61.3 \%)$ & $13,863(60.4 \%)$ & $36,767(61.7 \%)$ & $8,374(61.5 \%)$ & $8,539(60.5 \%)$ \\
\hline $50-59$ & $15,626(55.7 \%)$ & $74,623(55.6 \%)$ & 7,747 (56.2\%) & $|6,43|(55.3 \%)$ & $39,747(56.5 \%)$ & $9,285(56.3 \%)$ & 9,851 (55.5\%) \\
\hline $60-69$ & $37,85 \mathrm{I}(57.7 \%)$ & $142,639(57.7 \%)$ & $15,860(58.2 \%)$ & $31,867(57.3 \%)$ & $75,260(58.6 \%)$ & $18,705(58.4 \%)$ & $19,802(57.5 \%)$ \\
\hline 70-79 & $45,473(49.6 \%)$ & $134,802(49.6 \%)$ & $16,652(50.0 \%)$ & $34,625(49.3 \%)$ & $74,916(50.4 \%)$ & $20,099(50.2 \%)$ & $18,178(49.4 \%)$ \\
\hline$\geq 80$ & $35,322(45.6 \%)$ & $65,40 \mathrm{I}(45.5 \%)$ & $12,067(46.0 \%)$ & $21,938(45.3 \%)$ & $53,057(46.2 \%)$ & II,033 (46.1\%) & $9,696(45.4 \%)$ \\
\hline \multicolumn{8}{|c|}{ By sex (\% of total treated) } \\
\hline Male & $83,850(57.6 \%)$ & $274,816(57.2 \%)$ & $33,54 \mathrm{I}(40.0 \%)$ & $67,994(57.3 \%)$ & I59,235 (56.9\%) & $38,542(57.1 \%)$ & $37,617(56.9 \%)$ \\
\hline Female & $61,707(42.4 \%)$ & $205,292(42.8 \%)$ & $24,930(60.0 \%)$ & $50,730(42.7 \%)$ & $120,5 \mid 2(43.1 \%)$ & $28,954(42.9 \%)$ & $28,449(43.1 \%)$ \\
\hline \multicolumn{8}{|c|}{ By comorbidity (\% of total treated) } \\
\hline Hypertension & $82,240(56.5 \%)$ & $249,656(52.0 \%)$ & $33,328(57.0 \%)$ & $60,549(51.0 \%)$ & $|53,86|(55.0 \%)$ & $36,785(54.5 \%)$ & $35,676(54.0 \%)$ \\
\hline Diabetes & $38,28 \mathrm{I}(26.3 \%)$ & $76,817(16.0 \%)$ & $8,77 \mid(\mid 5.0 \%)$ & $26,119(22.0 \%)$ & $78,329(28.0 \%)$ & $24,636(36.5 \%)$ & 7,928 (I2.0\%) \\
\hline Heart failure & $43,667(30.0 \%)$ & $96,022(20.0 \%)$ & $|7,54|(30.0 \%)$ & $28,494(24.0 \%)$ & $83,924(30.0 \%)$ & 9,787 (I4.5\%) & $15,195(23.0 \%)$ \\
\hline Stroke & $18,486(12.7 \%)$ & $43,210(9.0 \%)$ & $3,508(6.0 \%)$ & $8,311(7.0 \%)$ & $27,975(10.0 \%)$ & $8,100(12.0 \%)$ & I,982 (3.0\%) \\
\hline \multicolumn{8}{|c|}{ By type of AF (\% of total treated) } \\
\hline NVAF & $125,342(86.1 \%)$ & $4 \mid 2,407(85.9 \%)$ & $50,391(86.2 \%)$ & $102,043(86.0 \%)$ & $240,528(86.0 \%)$ & 57,991 (85.9\%) & $56,366(85.3 \%)$ \\
\hline VAF & $20,215(13.9 \%)$ & $67,701(14.1 \%)$ & $8,080(13.8 \%)$ & $16,68 \mid(14.1 \%)$ & $39,219(14.0 \%)$ & $9,505(14.1 \%)$ & $9,700(14.7 \%)$ \\
\hline $\begin{array}{l}\text { By inpatient status } \\
\text { (\% of total treated) }\end{array}$ & $57,930(39.8 \%)$ & $190,879(39.8 \%)$ & $23,467(40.1 \%)$ & $46,933(39.5 \%)$ & I I2,967 (40.4\%) & $27,013(40.0 \%)$ & $25,718(38.9 \%)$ \\
\hline
\end{tabular}

Notes: aData from patients diagnosed and treated in the respective national health care systems; 'bome patients may have had more than one comorbidity. Abbreviations: AF, atrial fibrillation; NVAF, nonvalvular atrial fibrillation; VAF, valvular atrial fibrillation. 
Table 3 Inpatient and outpatient treatments used for AF, by country

\begin{tabular}{|c|c|c|c|c|c|c|c|}
\hline & Argentina & Brazil & Chile & Colombia & Mexico & Peru & Venezuela \\
\hline \multicolumn{8}{|l|}{ Outpatients } \\
\hline No treatment & 35,807 (24.6\%) & 87,860 (18.3\%) & $\mid 2,396(2 \mid .2 \%)$ & $26,594(22.4 \%)$ & $62,943(22.5 \%)$ & $|4,4| 7$ (21.4\%) & $|3,4| \mid(20.3 \%)$ \\
\hline VKA & 77,727 (53.4\%) & $279,423(58.2 \%)$ & $30,580(52.3 \%)$ & $53,663(45.2 \%)$ & $|57,2| 8(56.2 \%)$ & $37,933(56.2 \%)$ & $38,014(57.5 \%)$ \\
\hline VKA + ASA & $18,340(12.6 \%)$ & 84,499 (I7.6\%) & I I,870 (20.3\%) & 33,955 (28.6\%) & $46,438(16.6 \%)$ & 10,597 (I5.7\%) & 8,325 (12.6\%) \\
\hline $\begin{array}{l}\text { VKA + ASA + } \\
\text { antiplatelets }\end{array}$ & 13,682 (9.4\%) & $28,326(5.9 \%)$ & 3,625 (6.2\%) & $4,5 \mathrm{I} 2(3.8 \%)$ & $|3|$,48 (4.7\%) & 4,549 (6.7\%) & $6,316(9.6 \%)$ \\
\hline \multicolumn{8}{|l|}{ Inpatients } \\
\hline UFH & $38,002(65.6 \%)$ & $|02,94|(53.9 \%)$ & $13,172(56.1 \%)$ & 29,676 (63.2\%) & 69,249 (61.3\%) & 14,709 (54.5\%) & 15,760 (6I.3\%) \\
\hline LMWH & $|5,64|(27.0 \%)$ & 70,740 (37.1\%) & $8,300(35.4 \%)$ & $12,470(26.6 \%)$ & 31,970 (28.3\%) & $9,792(36.3 \%)$ & 7,515 (29.2\%) \\
\hline VKA & 4,287 (7.4\%) & $17,198(9.0 \%)$ & I,995 (8.5\%) & 4,787 (I0.2\%) & I I,749 (I0.4\%) & $2,5 \mathrm{I} 2(9.3 \%)$ & $2,443(9.5 \%)$ \\
\hline
\end{tabular}

Abbreviations: ASA, acetylsalicylic acid; LMWH, low-molecular-weight heparin; UFH, unfractionated heparin; VKA, vitamin K antagonist.

increased prevalence of AF in association with increasing age, suggest there will be an increase over time in the overall prevalence of $\mathrm{AF}$, and a similar increase in the expected number of patients with AF. This aging population trend is mirrored elsewhere, and underscores the burden associated with age-related diseases and comorbidities such as AF and stroke. ${ }^{39,40}$ It will be important to ensure that local and national health care systems are prepared to effectively address this expected increase in the prevalence of $\mathrm{AF}^{41}$

Two studies in the Spanish population identified the risk factors frequently associated with $\mathrm{AF}$, which included cardiovascular disease, hypertension, aging, left ventricular hypertrophy, diabetes, ischemic cardiomyopathy, ventricular dysfunction, and widening of the atrial diameter $>45 \mathrm{~mm} \cdot{ }^{42,43}$ In this study, hypertension was present in over $50 \%$ of patients with AF, heart failure in $14.5 \%-30 \%$, and diabetes $(12 \%-36.5 \%)$, and the prevalence of these comorbidities defines the stroke risk for a significant proportion of these patients as high, as assessed by $\mathrm{CHADS}_{2}$ or $\mathrm{CHADS}_{2} \mathrm{VASc}_{2}$. Despite this potentially high stroke risk population, oral anticoagulation with VKA monotherapy as recommended by the guidelines accounted for only $54 \%$ of all outpatient treatment in the countries analyzed. Among hospitalized patients, the data show that a high percentage $(21 \%)$ of patients with $\mathrm{AF}$ receive no prophylactic treatment for reducing stroke risk. Older patients with AF are at a higher risk of bleeding than younger patients, and this can dissuade physicians from prescribing oral anticoagulation. ${ }^{44}$ While this and other potential reasons, including cost and other issues, might explain the high proportion of patients not receiving anticoagulation, there is no way of positively identifying the reasons from the data available. Additionally, in a significant proportion of cases, warfarin was used in combination with ASA or with dual antiplatelet therapy. While available guidelines for AF treatment in 2010 recommended oral VKA monotherapy, it is possible some patients had additional comorbidities that justified triple therapy, despite the associated increased risk of bleeding. Since the period covered by this study, further guidelines have been published that help to better stratify patients by stroke risk, allowing for identification of both patients who are truly at low risk of stroke, and those who may benefit most from treatment. ${ }^{7,45}$ Recent guidelines have also included the use of oral anticoagulants such as dabigatran, rivaroxaban, and apixaban. These anticoagulants are alternatives to warfarin for thromboprophylaxis that obviate the need for regular coagulation monitoring, and that may be associated with improved efficacy or bleeding profiles in patients with $\mathrm{AF}^{7,46}$

In this context, Ruíz et al performed a prospective study in patients with chronic nonvalvular AF treated at two cardiology outpatient clinics to analyze major events (death, systemic embolism, and severe hemorrhage) by treatment group. ${ }^{47}$ Results from the study showed that $93 \%$ of the nonanticoagulant cases were receiving antiplatelets, of which ASA was used in $92 \%$ of the cases. Labadet et $\mathrm{al}^{48}$ conducted another multicenter study, in Argentina, which followed 840 consecutive patients ( $75 \%$ of whom were $\geq 65$ years of age) with chronic AF at high risk of stroke, of whom $48.5 \%$ were treated with oral anticoagulants; medical contraindications to anticoagulation existed in only $17.1 \%$ of the patients. Results from this study also showed that $13.7 \%$ of the study sample had a history of embolic events, but only $20 \%$ of these were receiving anticoagulant treatment when the stroke occurred.

\section{Study limitations}

There is a lack of accurate epidemiology data for AF in Latin American countries. As such, the purpose of this analysis was to utilize local data wherever possible and where no local data were available, extrapolate from prevalence in other countries. Therefore, in the absence of local epidemiological studies, estimates for prevalence are currently limited to 
such extrapolations as this one. One strength of this database analysis is the large numbers of patients that were included. However, the different national health care system databases used for this study employ different reporting methods, and equivalent information was not always available across all of them. Therefore, this study extrapolated from the available data using information taken from the published literature. While local publications were used where possible, international data were also used. Treatment distributions, for example, were estimated from both the available data, which included only a proportion of patients, and local publications. Therefore, the treatment patterns identified here should be challenged and corroborated with field research locally.

Although an extensive search of the specialized medical literature in Latin America was carried out, none of the publications found referred to specific epidemiologic data for each country. Estimates for the prevalence of AF generated by this study for the selected Latin American countries were based on patterns of AF seen internationally, but also take into consideration specific risks resulting from the differing population pyramids and comorbidities of each country analyzed. However, owing to population differences, stroke risk estimates based on Western populations may not be directly applicable. ${ }^{49}$ Indeed, because of variations in other factors associated with each country, even estimates based on similar ethnic populations in other countries may not be directly applicable. ${ }^{50}$ As more country- and region-specific data become available, further research will be necessary to confirm the conclusions made here using limited data.

\section{Conclusion}

The diversity in the populations and comorbidities seen in this study, as well as the known underreporting of strokes, may warrant further study. However, given the high proportion of patients with AF who received no prophylactic therapy for stroke despite available effective treatments, the results of this study highlight a need for increased awareness of AF and the burden of this condition on the Latin American health care system.

\section{Acknowledgments}

This study was funded by Pfizer Inc. The authors would like to thank Alfonso Rosado, Lourdes Garcia, and Gerardo Luna from Links and Links (Tlalpan, México DF) for assistance with data acquisition and analysis; and Andy Shepherd and Meredith Kalish at Caudex Medical for medical writing and editorial assistance, both funded by Pfizer Inc.

\section{Disclosure}

All authors take responsibility for all aspects of the reliability and freedom from bias of the data presented and their discussed interpretation. At the time of study, Alexandra Haddad was an employee of Pfizer Mexico, and Luz Cubillos, Andreas Kuznik, and Joaquin Mould-Quevedo were employees of Pfizer Inc. The authors have no further conflicts of interest in this work.

\section{References}

1. You JJ, Singer DE, Howard PA, et al. Antithrombotic therapy for atrial fibrillation: Antithrombotic Therapy and Prevention of Thrombosis, 9th ed: American College of Chest Physicians Evidence-Based Clinical Practice Guidelines. Chest. 2012;141(Suppl 2):e531S-e575S.

2. Fuster V, Rydén LE, Cannom DS, et al. 2011 ACCF/AHA/HRS focused updates incorporated into the ACC/AHA/ESC 2006 guidelines for the management of patients with atrial fibrillation: a report of the American College of Cardiology Foundation/American Heart Association Task Force on practice guidelines. Circulation. 2011;123(10):e269-e367.

3. Camm AJ, Kirchhof P, Lip GY, et al. Guidelines for the management of atrial fibrillation: the Task Force for the Management of Atrial Fibrillation of the European Society of Cardiology (ESC). Eur Heart J. 2010;31(19):2369-2429.

4. Go AS, Hylek EM, Phillips KA, et al. Prevalence of diagnosed atrial fibrillation in adults: national implications for rhythm management and stroke prevention: the AnTicoagulation and Risk Factors in Atrial Fibrillation (ATRIA) Study. JAMA. 2001;285(18):2370-2375.

5. Mukamal KJ, Tolstrup JS, Friberg J, Jensen G, Grønbaek M. Alcohol consumption and risk of atrial fibrillation in men and women: The Copenhagen City Heart Study. Circulation. 2005;112(12): 1736-1742.

6. Hart RG, Pearce LA, Aguilar MI. Meta-analysis: antithrombotic therapy to prevent stroke in patients who have nonvalvular atrial fibrillation. Ann Intern Med. 2007;146(12):857-867.

7. Camm AJ, Lip GY, De Caterina R, et al. 2012 focused update of the ESC Guidelines for the management of atrial fibrillation: an update of the 2010 ESC Guidelines for the management of atrial fibrillation. Developed with the special contribution of the European Heart Rhythm Association. Eur Heart J. 2012;33(21):2719-2747.

8. Hirsh J, Guyatt G, Albers GW, Harrington R, Schünemann HJ; American College of Chest Physicians. Executive summary: American College of Chest Physicians Evidence-Based Clinical Practice Guidelines (8th ed). Chest. 2008;133(Suppl 6):71S-109S.

9. Lip GY, Brechin CM, Lane DA. The global burden of atrial fibrillation and stroke: a systematic review of the epidemiology of atrial fibrillation in regions outside North America and Europe. Chest. 2012;142(6):1489-1498.

10. Bennett D, Abate J, Abrahamson PE. Characteristics of patients with venous thromboembolism and atrial fibrillation in Venezuela. $B M C$ Public Health. 2011;11:415-420.

11. Lavados PM, Sacks C, Prina L, et al. Incidence, case-fatality rate, and prognosis of ischaemic stroke subtypes in a predominantly HispanicMestizo population in Iquique, Chile (PISCIS project): a communitybased incidence study. Lancet Neurol. 2007;6(2):140-148.

12. Castañeda-Guarderas A, Beltrán-Ale G, Casma-Bustamante R, RuizGrosso P, Málaga G. [Registry of patients with stroke stated in a public hospital of Peru, 2000-2009]. Rev Peru Med Exp Salud Publica. 2011;28(4):623-627. Spanish.

13. The World Bank, Latin America and Carribean. Available from: http:// data.worldbank.org/region/latin-america-and-carribean. Accessed June 18, 2014.

14. Healey JS, Oldgren J, Parekh A, et al. Global variations in the 1-year rates of death and stroke in 15,432 patients presenting to the emergency department with atrial fibrillation in 47 countries: The RE-LY AF Registry. Presented at: The European Society of Cardiology Congress; August 29, 2012; Munich, Germany. 
15. Iturralde-Torres P, Lara-Vaca S, Cordero-Cabra A, et al. [Design of a multicenter registry to evaluate rhythm versus rate control in atrial fibrillation: Atrial Fibrillation Mexican Registry (ReMeFA).] Arch Cardiol Mex. 2011;81(1):13-17. Spanish.

16. Sistema Nacional de Información en Salud [webpage on the Internet]. Egresos hospitalarios Morbilidad 2004-2008 [Hospital morbidity discharge statistics from the National Information Health System 2004-2008]. Available from: http://www.sinais.salud.gob.mx/ basesdedatos/. Accessed June 18, 2014. Spanish.

17. Dirección General de Epidemiología [homepage on the Internet]. Anuarios Estadísticos Morbilidad 2004-2010 [Directorate General of Epidemiology Annual Morbidity Statistics 2004-2010]. Available from: http://www. epidemiologia.salud.gob.mx/. Accessed July 9, 2014. Spanish.

18. Ministerio de Salud y Ambiente de la Nación Argentina [homepage on the Internet]. Anuarios Estadísticos de Morbilidad (Egresos Hospitalarios) 2005, 2006 y 2007 [Ministry of health and environment of Argentina. Annual Morbidity Statistics (Hospital discharge) 2005, 2006 and 2007]. Available from: http://www.msal.gov.ar. Accessed June 18, 2014. Spanish.

19. Dirección de Estadísticas e Información en Salud [webpage on the Internet]. Anuarios Estadísticos de Morbilidad (Egresos Hospitalarios) 2005, 2006 y 2007 [Directorate of Statistics and Health Information Annual Morbidity Statistics 2005, 2006 and 2007]. Available from: http://www.deis.gov.ar/Publicaciones/arbol_tematico.asp. Accessed June 18, 2014. Spanish.

20. Departamento de Informática do SUS [webpage on the Internet]. Informações de Saúde/Epidemiológicas e Morbidade/Morbidade Hospitalar do SUS 2004-2010 [Information Department of SUS. Health Information/Epidemiologic and Morbidity/Hospital Morbidity the SUS 2004-2010]. Available from: http://www2.datasus.gov.br/DATASUS/ index.php?area=0203. Accessed June 18, 2014. Spanish.

21. Departamento de Informática do SUS [webpage on the Internet]. Informações de Saúde/Estatísticas Vitais/Mortalidade - 1996 a 2009, pela CID-10 [Information Department of SUS. Health Information/Vital Statistics/Mortality - 1996-2009, by CID-10]. Available from: http:// www2.datasus.gov.br/DATASUS/index.php?area=0205. Accessed June 18, 2014. Spanish.

22. Agencia Nacional de Vigilância Sanitaria [National Agency of Health Vigilance] [webpage on the Internet]. Available from: http://portal.anvisa. gov.br/wps/portal/anvisa/home. Accessed March 22, 2011. Spanish.

23. Departamento de Estadística e información en Salud Chile [webpage on the Internet]. Estadísticas de Morbilidad/Egresos Hospitalarios 2004-2008 [Department of Statistics and health information of Chile. Morbidity Statistics/Hospital Discharges 2004-2008]. Available from: http://www deis.cl/todas-las-categorias/?p=47. Accessed March 30, 2011. Spanish.

24. Departamento de Estadística e información en Salud Chile [webpage on the Internet]. Estadísticas de Atención en Salud/Estadísticas Hospitalarias 2004-2008 [Department of Statistics and health information of Chile. Health Attention Statistics/Hospital Statistics 2004-2008]. Available from: http://www.deis.cl/todas-las-categorias. Accessed June 18, 2014. Spanish.

25. Compendio Estadístico de Salud Chile [webpage on the Internet]. Estadísticas en Salud 2010 [Statistical Compendium of Health in Chile Health Statistics 2010]. Available from: http://www.ine.cl/canales/menu/ publicaciones/compendio_estadistico/compendio_estadistico2010.php. Accessed June 18, 2014. Spanish.

26. Ministerio de Protección Social [webpage on the Internet]. Estadísticas/ Salud/Salud Publica/Anuarios Estadísticos (Egresos Hospitalarios 2007-2010) [Ministry of Social Protection. Health Statistics/Public Health/Annual Statistics (Hospital Discharges 2007-2010)]. Available from: http://www.minproteccionsocial.gov.co/salud/default.aspx. Accessed June 18, 2014. Spanish.

27. Instituto Nacional de Salud [webpage on the Internet]. Estadísticas de la Vigilancia en Salud Pública/Boletines Estadísticos Semanales 2010 [National Institute of Health. Vigilance Statistics in Public Health/ Weekly Statistical Bulletins 2010]. Available from: http://www.ins.gov. co/?idcategoria=1729. Accessed April 5, 2011. Spanish.
28. Ministerio del Poder Popular para la Salud [webpage on the Internet]. Planes y Proyectos/Dirección del MPPS/Epidemiología [Ministry of Health. Plans and Projects/Directorate of MPPS/Epidemiology]. Available from: http:/www.mpps.gob.ve/index.php?option=com_co ntent\&view=article\&id=549\&Itemid=915. Accessed June 18, 2014. Spanish.

29. Ministerio de Salud Perú [homepage on the Internet]. Estadísticas/ Egresos Hospitalarios 2005-2010 morbilidad hospitalaria [Ministry of Health Peru. Hospital Discharge Statistics 2005-2010 hospital morbidity]. Available from: http://www.minsa.gob.pe/. Accessed June 18, 2014. Spanish

30. Borenstein M, Hedges L, Higgins J, Rothstein H. Comprehensive Metaanalysis (Version 2). Englewood, NJ: Biostat; 2005.

31. Perel C, Casey M. Anticoagulación en la hipertensión pulmonar. [Anticoagulation in pulmonary hypertension]. Insuf Cardiaca. 2008;3 125-128. Spanish.

32. Avila CW, Aliti GB, Feijó MK, Rabelo ER. Pharmacological adherence to oral anticoagulant and factors that influence the international normalized ratio stability. Rev Lat Am Enfermagem. 2011;19(1):18-25.

33. Sandoval R, Navarro J. Manejo de la fibrilación auricular en la paciente obstétrica [Atrial fibrillation treatment in obstetric patient]. Rev Fac Med. 2010;58:324-330. Spanish.

34. Montecinos H. Anticoagulación en Geriatría II: Prevención de Complicaciones [Anticoagulation in geriatrics II: prevention of complications]. Medwave. 2006;6(3):e1140. Spanish.

35. Lloyd-Jones DM, Wang TJ, Leip EP et al. Lifetime risk for development of atrial fibrillation: the Framingham Heart Study. Circulation. 2004;110(9):1042-1046.

36. Alonso A, Agarwal SK, Soliman EZ et al. Incidence of atrial fibrillation in whites and African-Americans: the Atherosclerosis Risk in Communities (ARIC) study. Am Heart J. 2009;158(1):111-117.

37. Wolf PA, Abbott RD, Kannel WB. Atrial fibrillation as an independent risk factor for stroke: the Framingham Study. Stroke. 1991;22(8):983-988.

38. Frewen J, Finucane C, Cronin H, et al. Factors that influence awareness and treatment of atrial fibrillation in older adults. QJM. 2013;106(5): 415-424.

39. Ball J, Carrington MJ, McMurray JJ, Stewart S. Atrial fibrillation: profile and burden of an evolving epidemic in the 21 st century. Int J Cardiol. 2013;167(5):1807-1824.

40. who.int. [webpage on the Internet]. Cardiovascular disease. World Health Organization; 2014. Available from: http://www.who.int/cardiovascular_diseases/priorities/en/index.html. Accessed June 18, 2014.

41. Escobar MC, Petrásovits A, Peruga A, Silva N, Vives M, Robles S. [Myths about the prevention and control of non-communicable diseases in Latin America]. Salud Publica Mex. 2000;42(1):56-64. Spanish.

42. Cea-Calvo L, Redón J, Lozano JV, et al. [Prevalence of atrial fibrillation in the Spanish population aged 60 years or more. The PREV-ICTUS study]. Rev Esp Cardiol. 2007;60(6):616-624. Spanish

43. Candel FJ, Matesanz M, Cogolludo F, et al. [Prevalence of atrial fibrillation and relationed factors in a population in the centre Madrid] An Med Interna. 2004;21(10):477-482. Spanish.

44. Sankaranarayanan R, Kirkwood G, Dibb K, Garratt CJ. Comparison of atrial fibrillation in the young versus that in the elderly: a review. Cardiol Res Pract. 2013;22:976976.

45. Taillandier S, Olesen JB, Clémenty N, et al. Prognosis in patients with atrial fibrillation and CHA2DS2-VASc Score $=0$ in a community-based cohort study. J Cardiovasc Electrophysiol. 2012;23(7):708-713.

46. Heidbuchel H, Verhamme P, Alings M, et al. European Heart Rhythm Association Practical Guide on the use of new oral anticoagulants in patients with non-valvular atrial fibrillation. Europace. 2013;15(5):625-651.

47. Ruíz M, Peñas E, Zapata F, Rubio M, Belsué V. Un protocolo prospectivo de anti coagulación oral en los pacientes con fibrilación auricular crónica no valvular: efectividad y seguridad en la práctica clínica diaria [A prospective protocol of oral anticoagulation in patients with chronic nonvalvular atrial fibrillation: effectiveness and safety in daily clinical practice]. Mapfre Medicina. 2004;15(4):233-243. Spanish. 
48. Labadet C, Liniado G, Ferreirós ER, et al. Resultados del Primer Estudio Nacional, Multicéntrico y Prospectivo de Fibrilación Auricular Crónica en la Republica Argentina [National, Multicentre and Prospective study of Chronic Atrial Fibrillation in the Republic of Argentina]. Rev Argentina Cardiol. 2001;69:49-67. Spanish.

49. Simpson JR, Zahuranec DB, Lisabeth LD, et al. Mexican Americans with atrial fibrillation have more recurrent strokes than do non-Hispanic whites. Stroke. 2010;41(10):2132-2136.
50. Romano JG, Arauz A, Koch S, et al. Disparities in stroke type and vascular risk factors between 2 Hispanic populations in Miami and Mexico City. J Stroke Cerebrovasc Dis. 2013;22(6):828-833.

\section{Publish your work in this journal}

The International Journal of General Medicine is an international, peer-reviewed open-access journal that focuses on general and internal medicine, pathogenesis, epidemiology, diagnosis, monitoring and treatment protocols. The journal is characterized by the rapid reporting of reviews, original research and clinical studies across all disease areas.
A key focus is the elucidation of disease processes and management protocols resulting in improved outcomes for the patient.The manuscript management system is completely online and includes a very quick and fair peer-review system. Visit http://www.dovepress.com/ testimonials.php to read real quotes from published authors.

Submit your manuscript here: http://www.dovepress.com/international-journal-of-general-medicine-journal 